\title{
Exploring the Relationship between Nursing Students' Resilience and Spirituality in a Critical Care, End-Of-Life Care Simulation
}

\author{
Michelle Allen $^{1 *}$, Maureen Emlund ${ }^{2}$, Michal Kozdronkiewicz ${ }^{3}$, Kristen Bayer ${ }^{4}$ and Tamara Bland ${ }^{5}$
}

${ }^{1} E d D, M S N, R N, C C R N, C N E, C H S E$, Department of Nursing, Dominican University

${ }^{2}$ MSN, RN, Department of Nursing, Dominican University

${ }^{3} \mathrm{MPHC}$, Department of Nursing, Dominican University

${ }^{4} M S N$, APN, FNP-C, Department of Nursing, Dominican University

${ }^{5} E d D c, M S N, R N$, Department of Nursing, Dominican University

Received: April 10, 2018; Accepted: April 17, 2018; Published: April 30, 2018

*Corresponding author: Michelle L Allen, EdD, MSN, RN, CCRN, CNE, CHSE, Lecturer, Dominican University, 7900 Division Street, River Forest, IL, USA. Tel: 847-261-2485; E-mail: mallen@dom.edu

\begin{abstract}
Background: The literature is deficient in exploring the relationship between undergraduate nursing students' resilience and spirituality. This deficit is particularly evident in simulation research. Researchers examined changes in resilience and spirituality in nursing students participating in a critical care end-of-life care simulation.
\end{abstract}

Method: Participants completed the Spiritual Intelligence SelfReport Inventory (SISRI-24) and the Resilience Scale before and after participating in the simulation.

Results: There were statistically significant changes in resilience and spirituality growth in the nursing students after participating in the simulation $(\mathrm{p}<0.05)$. In addition, a statistically significant $(\mathrm{p}<0.001)$ weak ( $\mathrm{r}=0.482)$ to moderately $(\mathrm{r}=0.530)$ positive correlation occurred in resilience and spirituality in the nursing students occurred before and after participating in the simulation respectively.

Conclusion: Nursing students experienced greater growth in resilience and spirituality after participating in the simulation. In addition, a correlation between resilience and spirituality levels was evident. Nursing educators should consider providing challenging simulations to nursing students.

Keywords: End-of-Life Care; Spirituality; Resilience; Undergraduate Nursing Education; Simulation

\section{Introduction}

The current cultural climate in nursing education encourages end-of-life care to be part of undergraduate nursing curriculum. This shift has been recommended by the Robert Wood Johnson Foundation and the American Association of Colleges of Nursing (2016) to support new nurses. It is well-identified that nursing students and nurses have experienced anxiety, fear, and burnout due to a lack of educational preparation with end-of-life care [1-9]. Burnout has been associated with a decline in healthcare professionals', including nursing's, resilience and spirituality $[10,11]$. As such, one undergraduate nursing program in suburban Chicago incorporated a holistic, end-of-life care simulation in their critical care nursing course and examined the impact of the curricular change on nursing students' resilience and spirituality.

\section{Literature Review}

\section{Simulation in Nursing Education}

According to Nelson (2016), many nursing schools are substituting $25-50 \%$ of clinical experiences with simulation. Nursing educators can use simulation to provide exposure to challenging patient scenarios while optimizing a safe environment $[12,13,44]$. Such scenarios can help the learners connect theory to practice while encouraging them to embrace their new roles as patient advocates during morally distressing situations, including end-of-life care [14,15].

\section{Spirituality and Resilience in Nursing}

Regardless of nursing specialty, nurses are placed in situations that require them to be resilient and overcome difficulties to flourish within their careers [16].Spirituality can assist with enhancing mental health outcomes and easing stress during challenging times [17]. For instance, Ormsby, Harrington, and Borbasi Ng (2017) utilized phenomenology to understand the lived experiences of ten Australian military nurses; the finding identified that spiritual care given to nurses helped them achieve greater resilience against the vulnerabilities of deployment.[45]

Mealer, Jones, and Moss (2012) interviewed thirteen nurses determined to be highly resilient and fourteen nurses diagnosed with post-traumatic stress disorder. The findings demonstrated that the highly resilient critical care nurses had greater spirituality, optimism, and were involved in a supportive network, including 
having a mentor that was deemed highly resilient. For the nurses with post-traumatic stress disorder (PTSD), they lacked optimism, a social network, a resilient role model, and experienced regret. Resilience was found to be key to a fulfilling critical care nursing career. Taheri-Kharameh (2016) found similar findings to Mealer, Jones, and Moss (2012) and found a positive correlation with spirituality and general health in 55 intensive care unit nurses in Iran ( $r=0.348)$. Similar to Mealer, Jones, and Moss (2012), Gaydos (2004) utilized cocreative aesthetic inquiry and found that a fruitful nursing career in hospice required nurses to enter the field with high resilience, spirituality, endurance, and previous exposure to loss and grief $[18,43]$.

The North Shore-LIJ Health System in New York recognized the need for resilience training and implemented a one day program for newly graduated nurses. The nurses reported feeling more reflective and self-aware after participation [19]. However, efforts in exploring resilience and spirituality should be examined at the pre-licensure nursing level as well.

\section{Spirituality and Resilience Development in Pre- licensure Nursing Education}

Stephens and Gunther (2016) conducted a multi-site study with70 junior level nursing students examining changes in selfidentified resilience when using the social-networking platform, Twitter, for class. The self-identified resilience surveys had a response rate of $23 \%$ in the experimental group; resilience scores increased by 87.5 when faculty-student engagement on Twitter focused on offering resilience-building resources [20].

Beauvais, Stewart, DeNisco, and Beauvais (2014) assessed 124 undergraduate and graduate nursing students' resilience, psychological empowerment, emotional intelligence (perceiving emotions), spiritual well-being, and academic success. Grade point average determined students' academic success. In the undergraduate nursing students, one correlation was found between emotional intelligence (perceiving emotions) and academic success $r(73)=-0.232, p=0.48$. While this does not explore a specific intervention, this study offers baseline resilience and spiritual well-being data for the undergraduate and graduate nursing student perspective [21].

Shores (2010) examined spiritual perspectives of 205 undergraduate nursing students at random. Many scored highly on the Spiritual Perspectives Scale (SPS), though the highest scores occurred in those associated with more frequent participation in religious activities. This research examined spirituality through a religious context, though Shore (2010) acknowledges that spirituality encompasses various meanings and dimensions. Similar to Shore (2010), Boswell, Cannon, and Miller (2013) also assessed students' perceptions on spirituality and also found that nursing students equated religion and spirituality [22, 23].

As opposed to at random and varying participants, as the case was with Shore (2010), Cilliers and Terblanche (2014) conducted a case study on 14 senior nursing students examining spirituality when working with a full nursing assignment in the hospital. Participants were asked to write an essay based upon their hospital experiences. Trustworthiness of the data was secured, and the findings demonstrated that students did not demonstrate spiritual intelligence; rather, internal conflict was evident and spiritual coping did not transpire [22,24].

Mitchell, Bennett, and Mandfrin-Ledet (2006) recommended nursing educators utilize case studies and care maps to enhance nursing students' development of spiritual and competent care to the end-of-life care patient. Despite this recommendation, understanding nursing students' personal growth of spirituality and resilience continues to be a shortfall in the literature. The literature is deficient of research examining resilience and spirituality development in nursing students in challenging patient situations such as end-of-life care. Rather, the literature mostly focuses on teaching undergraduate nursing students about spiritual care and resilience $[25,26]$. Furthermore, the current state of the literature typically involves exploration of undergraduate nursing students' development of resilience or spirituality, rarely both. The research at hand will explore development of resilience and spirituality in senior nursing students participating in an end-of-life care simulation.

\section{Theoretical Framework}

The Theory of Transformative Coping (TTC) guided the research. TTC identifies that inherent creativity and spirituality can enhance positive emotions and resilience during times of stress [27]. TTC incorporates Frederickson's Theory of Positive Emotions and Lazarus and Folkman's Stress and Coping Model [27]. Specifically, once a stressor has been identified, cognitive appraisal occurs. From there, mobilizing resources transpires (through creativity and spirituality) leading to emotion-focused strategies, problem-focused strategies, hope, self-esteem, and examination of life's meaning. In one of the last steps, the negative thoughts and emotions will turn into positive ones, yielding to greater resilience, ability to cope and reappraisal of the stressor [28].

\section{Problem Statement}

The current state of the literature lacks robust research using the TTC to examine if a relationship between spirituality and resilience exists. Furthermore, the problem at hand is that little research is available that explores the relationship between spirituality and resilience in undergraduate nursing students participating in an end-of-life care simulation. The purpose of this research is to explore whether or not the TTC is applicable to nursing students overcoming challenges while tending to the holistic needs of a simulated dying patient.

\section{Research Questions}

The posed research questions are:

1. Is there a statistically significant difference in undergraduate nursing students' resilience scores before and after participating in a holistic, critical care end-of-life care simulation?

2. Is there a statistically significant difference in undergraduate nursing students' spirituality scores before and after 
participating in a holistic, critical care end-of-life care simulation?

3. Is there a correlation between resilience and spirituality scores in undergraduate nursing students participating in a holistic, critical care end-of-life care simulated patient?

\section{Methods}

This quantitative research was two-pronged in design; the study design was quasi-experimental and correlational as changes in resilience and spirituality were isolated as well as examined for a possible relationship. The research included 48 undergraduate, senior nursing students who were in their final week of a critical care nursing course in the spring term of 2018. The study also incorporated a correlational analysis. The nursing students were in their final rotation prior to clinical role transition. The convenience sample required at least 44 participants and was based on a priori effect size using Cohen's $d$ of 0.5 , power of 0.90 , and alpha error probability of 0.05 , verified through $G^{*}$ Power 3.1.9.2 (29). Prior to performing the study, on-site IRB approval was secured.

\section{Instrumentation}

\section{Resilience Scale}

Resilience was measured using the Resilience Scale. The Resilience Scale contains 24 questions, uses a Likert scale that asks the participant to respond with a range from one to seven, which represents strongly disagree to strongly agree [30]. The Resilience Scale demonstrated a Cronbach's alpha coefficient ranging from 0.85 to 0.94 and an internal consistency ranging from 0.91 to 0.94 across multiple studies [30]. Furthermore, two nursing researchers confirmed excellent construct and content validity was identified [30]. Multiple researchers have used the Resilience Scale [21,30-32).

\section{Spiritual Intelligence Self-Report Inventory}

Spirituality was measured by the Spiritual Intelligence SelfReport Inventory (SISRI-24). The tool contains 24 questions asking the participants to use a Likert Scale from zero to four to describe them; the numbers represent the range from "not at all true of me" to "completely true of me [33]. Spiritual intelligence requires one to be in-touch with their perspective on what they value and hold sacred [34]. Being self-aware allows for maturity and ability to adjust to challenges in life [35].

King (2008) created the SISRI-24 and found it to be a highly reliable measure of spiritual intelligence $(\alpha=0.92)$ and with construct validity in 305 undergraduate students. Further testing of the instrument included test-retest reliability was $r=0.89(p<0.001)$ and a full factor analysis when studying 25 undergraduate students [36]. Multiple recent studies have assessed, confirmed reliability and validity of the SISRI-24 $[35,37,38]$. Considering this and the original intention was to measure undergraduate students' spirituality, this tool was deemed most appropriate

\section{Simulation Development and Simulation Implementation}

In the beginning of the semester, nursing students enrolled in an adult critical care course signed up for a one hour simulation that would occur in the final week of the course. Students were asked to sign up for a time slot through a scheduling software website. The students' identities and time slots were marked as 'private,' meaning no one other than the primary investigator could see who signed up for which time slot. This simulation had three to five students per slot and was conducted sixteen times over two days in the spring semester of 2018.

Students were given prep work, which required them to answer questions about providing holistic care to end-of-life care patients prior to coming to the simulation. In addition, since the simulation was offered during the final week of the class, all nursing students were given class instruction of how to provide holistic care to a critically ill adult patient across the eight week course. In addition, all of the nursing students completed a total of 91 clinical hours in a high acuity telemetry or intensive care unit prior to participating in the simulation.

The students were asked to arrive ten to fifteen minutes early for the simulation, which included 30 minutes of exposure to the simulated patient and a 30 minute debriefing. At that time, students were provided information about the study from the primary investigator, signed consent form, and filled out the initial Resilience Scale and SISRI-24 questionnaires if volunteering to participate. From there, the nursing students were given report on a simulated critically ill, geriatric oncology patient.

The simulated patient was a high-fidelity mannequin dressed to resemble an elderly female. The patient was on multiple vasopressors, Amiodarone, intravenous fluids, receiving a blood transfusion, and had a Morphine Sulfate pain-control analgesia pump; all medications were administered through a triple lumen catheter in the left subclavian vein. Also, the patient had continuous blood pressure monitoring per a right arterial line. An electronic health record, including e-MAR and physician's orders, was made available to the students on a laptop in the room. The nursing students were able to obtain the Morphine Sulfate intravenous push medication from the Pyxis.

The patient moaned in pain and did not have family at the bedside. The nursing students were required to provide comfort care, including administering pain medication and turning off the vasopressors and blood transfusion. In addition, the students had to recognize various cardiac arrhythmias, including identifying atrial fibrillation on initial assessment. After one of the students pushed Morphine Sulfate, the patient went into ventricular fibrillation and then a systole. The students notified the physician and students provided post-mortem care to the patient.

Once post-mortem care was completed, the simulation was completed. The students filled out the Resilience Scale and SIRSI-24 again, which required approximately five minutes of time. From there, the scales were submitted to the primary investigator; 
students were able to select a candy bar as remuneration for the time, energy, and honest sharing of thoughts. After that, a 30 minute debriefing followed. The debriefing using structured questions that reflected on the simulation, providing end-oflife care that included holistic care, coping with loss, feelings surrounding a patient dying without family at the bedside, and their state of mind when turning off the intravenous pumps and intravenously pushing the Morphine Sulfate.

\section{Results}

The simulation was required for 48 senior nursing students to attend, though participation in the research was optional. The response rate of survey submission was $100 \%$. The students were asked to check that their surveys were fully completed prior to submitting them to the primary investigator.

Statistical analysis was conducted using paired samples t-test and Pearson's r correlation in SPSS. When applicable, a Cohen's

\begin{tabular}{|c|c|c|c|c|c|}
\hline & $\begin{array}{c}\text { Pre-Intervention } \\
\text { Score }\end{array}$ & $\begin{array}{l}\text { Post-Intervention } \\
\text { Score }\end{array}$ & $\begin{array}{c}\text { 95\% Confidence } \\
\text { Interval }\end{array}$ & $\begin{array}{l}\text { Change in Mean } \\
\text { Score Percentage }\end{array}$ & $\mathbf{p}$ \\
\hline Resilience & $\begin{array}{l}M=139.02 \\
(S D=14.07)\end{array}$ & $\begin{array}{l}M=142.27 \\
(S D=15.22)\end{array}$ & 1.07 to 5.43 & $2.34 \%$ & $\begin{array}{c}\mathrm{t}(47)=2 . .99, \mathrm{p}=0.004 \\
\text { (two-tailed) }\end{array}$ \\
\hline Spirituality & $\begin{array}{c}\mathrm{M}=62.44 \\
(\mathrm{SD}=13.28)\end{array}$ & $M=67.00,(S D=13.54)$ & 2.91 to 6.22 & $7.30 \%$ & $\begin{array}{c}\mathrm{t}(47)=5.54, \mathrm{p}=0.000 \\
\text { (two-tailed) }\end{array}$ \\
\hline
\end{tabular}

In order to examine a relationship between resilience and spirituality, including assessing the impact of the simulation on the nursing students, a Pearson's product-moment correlation coefficient was calculated for pre-simulation and post-simulation scores. There was a weak, positive correlation between presimulation scores of resilience and spirituality, $r=0.482, n=48$, $\mathrm{p}=0.001$ (two-tailed). In addition, there was a moderate, positive correlation between post-simulation scores of resilience and spirituality, $r=0.530, n=48, p=0.000$ (two-tailed).

\section{Discussion}

TTC identifies that a relationship exists between spirituality and resilience; this research supports that a correlation of weak to moderate size exists between spirituality and resilience when nursing students participate in a critical care end-of-life care simulation [27]. Understanding the existence of the relationship as well as appreciating increases in nursing students' growth in spirituality and resilience encourages nursing educators to provide challenging opportunities to students. Challenging the nursing students will help them build a skillset, including confidence, necessary for a rewarding career [39].

An interesting observation was to see the nursing students provide holistic care to the patient during post-mortem care. Some of the groups held a moment of silence, while one group verbally prayed over the patient after closing the body bag. Incorporating such care was not discussed or described in the course, which is what made these moments remarkable to observe. d was utilized to assess effect size. All data was assessed for missing data and outliers prior to statistical analysis, including for linearity.

A paired-samples t-test was conducted to evaluate the impact of participating in an end-of-life care simulation on nursing students' resilience on the Resilience Scale and SISRI-24. There Resilience Scale from pre-simulation $(M=139.02, S D=14.07)$ to post-simulation $(M=142.27, S D=15.22), \mathrm{t}(47)=2 . .99, p=0.004$ (two-tailed). The mean increase in resilience scores was 3.25 with a $95 \%$ confidence interval ranging from 1.07 to 5.43 . The Cohen's d statistic (0.22) indicated a small effect size. There was a statistically significant in spirituality scores on the SISRI-24 from pre-simulation $(M=62.44, S D=13.28)$ to post-simulation $(M=67.00, S D=13.54), \mathrm{t}(47)=5.54, p=0.000$ (two-tailed). The mean increase in spirituality was 4.56 with a $95 \%$ confidence interval ranging from 2.91 to 6.22 . The Cohen's d statistic (0.33) indicated a small effect size. (Table 1 ) was a statistically significant increase in resilience scores on the

\section{Limitations and Recommendations for Future Research}

This research was conducted at one program in suburban Chicago and with one term of students. A recommendation for future research would be to implement this across an undergraduate program and multi-site. In addition, the research did not incorporate how debriefing impacted the nursing students' development of resilience and spirituality. Many students verbalized gains in resilience and spirituality in the debriefing; a recommendation for future research would include assessing quantitatively and qualitatively how debriefing impacts nursing students' resilience and spirituality in an end-of-life care simulation. Also, another recommendation would be to inquire about the feelings and actions taken during post-mortem care, such as praying over the patient. Furthermore, future research can examine if resilience and spirituality development is impacted by age of the simulated patient, such as a pediatric patient.

\section{Conclusion}

Due to the physical, emotional, and psychological demands of nursing, particularly tending to the needs of dying patients, a nurse's resilience is placed at risk [40]. Hodges et al. (2005) identified that nursing education must support nursing students development of resilience through the use of various pedagogical teaching methods. Since nearly $20 \%$ of new graduate nurses leave the profession within the first year of practice, nursing educators must provide opportunities to nursing students to build resilience $[41,42]$. 
Shores (2010) recommended nursing educators having greater awareness of nursing students' spiritual perspectives to enhance opportunities to link theory and practice. Despite those recommendations and requests for further research, the literature has been short of research examining various pedagogies that can support the development of resilience and spirituality in undergraduate nursing students. This study began to address this by studying resilience and spirituality development in undergraduate nursing students in a holistic, end-of-life care simulation. Simulation can serve as a safe environment to explore resilience and spirituality in difficult patient scenarios, including providing holistic to an end-of-life care patient.

\section{Acknowledgements}

Thank you to Dominican University's Nursing Department and College of Health Sciences, including Dean Dhanwada, for supporting implementation of simulation in healthcare education.

\section{References}

1. Kopp W, Hanson MA. High-fidelity and gaming simulations enhance nursing education in end-of-life care. Clinical Simulation in Nursing. 2012; 8(3): e97-e102. DOI: 10.1016/j.ecns.2010.07.005

2. American Association of Colleges of Nursing. ELNEC fact sheet. 2016.

3. Allen ML. Examining nursing students' stress in an end-of-life care simulation. Clinical Simulation in Nursing. 2018. 14(1): 21-28. DOI: 10.1016/j.ecns.2017.10.006

4. Caton AP, Klemm P. Introduction of novice oncology nurses to end of-life care. Clinical Journal of Oncology Nursing. 2006; 10(5):605608. DOI: $10.1188 / 06 . C J O N .604-608$

5. Gillan PC, Parameter G, Van der Riet PJ, Jeong S. The experience of end of life care simulation at a rural Australian university. Nurse Education Today. 2013; 33(11):1435-1439. DOI: 10.1016/j. nedt.2012.11.015

6. Holms N, Milligan S, Kydd A. A study of the lived experiences of registered nurses who have provided end-of-life care within an intensive care unit. Int J Palliat Nurs. 2014; 20(11):549-556. DOI: 10.12968/ijpn.2014.20.11.549.

7. Kwekkeboom KL, Vahl C, Eland J. Companionship and education: A nursing student experience in palliative care. J Nurs Educ. 2005 44(4):169-176.

8. Leighton K, Dubas J. Simulated death: An innovative approach to teaching end-of-life care. Clinical Simulation in Nursing. 2009; 5(6): e223-e230.

9. Sampaio AV, Comassetto I, Faro A, Santos RM, Monteiro FS. The experience of nursing students facing death and dying. Investigacion \& Educacion en Enfermeria.2015; 33(3):305-314. DOI: 10.17533/ udea.iee.v33n2a13

10. Mealer M, Jones J, Newman J, McFann KK, Rothbaum B, Moss M. The presence of resilience is associated with a healthier psychological profile in intensive care unit (ICU) nurses: results of a national survey. Int J Nurs Stud. 2012; 49(3):292-299. DOI: 10.1016/j. ijnurstu.2011.09.015.

11. McGarry S, Girdler S, McDonald A, Valentine J, Lee SL, Blair E, et al. Pediatrics health-care professionals: relationships between psychological distress, resilience and coping skills. Journal of Pediatrics and Child Health. 2013; 49(9):725-732. DOI: 10.1111/ jpc.12260

12. Berragan L. Simulation: An effective pedagogical approach for nursing? Nurse Educ Today. 2011; 31(7):660-663. D0I: 10.1016/j. nedt.2011.01.019

13. Lavoie P, Clarke SP. Simulation in nursing education. Nursing. 2017; 47(7):18-20. DOI: 10.1097/01.NURSE.0000520520.99696.9a

14. Gropelli TM. Using active simulation to enhance learning of nursing ethics. J Contin Educ Nurs. 2010; 41(3):104-105. doi: 10.3928/00220124-20100224-09

15. Ouyang JR, Stanley N. Theories and research in educational technology and distance learning instruction through Blackboard. Universal Journal of Educational Research. 2014; 2(2):161-172.

16. Hodges HF, Keeley AC, Grier EC. Professional resilience, practice longevity, and Parse's Theory for Baccalaureate Education. J Nurs Educ. 2005; 44(12):548-554.

17. Reinert KG, Koenig HG. Re-examining definitions of spirituality in nursing research. J Adv Nurs. 2013; 69(12):2622-2634. DOI: 10.1111/jan.12152

18. Mealer M, Jones J, Moss M. A qualitative study of resilience and posttraumatic stress disorder in United States ICU nurses. Intensive Care Med. 2012; 38(9):1445-1451. DOI: 10.1007/s00134-012-2600-

19. Richez M. Resilience-building strategies for nurses in transition. J Contin Educ Nurs. 2014; 45(2):54-55. DOI: 10.3928/0022012420140124-12.

20. Stephens TM, Gunther ME. Twitter, millennials, and nursing education research. Nurs Educ Perspect. 2016; 37(1):23-27

21. Beauvais AM, Stewart JG, DeNisco S, Beauvais JE. Factors related to academic success among nursing students: A descriptive correlational research study. Nurse Educ Today. 2014; 34(6):918923. DOI: 10.1016/j.nedt.2013.12.005

22. Shores CI. Spiritual perspectives of nursing students. Nurs Educ Perspect. 2010; 31(1):8-11.

23. Boswell C, Cannon SB, Miller J. Students' perceptions on holistic care. Nurs Educ Perspect. 2013; 34(5):329-333

24. Cilliers F, Terblanche $\mathrm{L}$. The role of spirituality in coping with the demands of the hospital culture amongst fourth-year nursing students. Int Rev Psychiatry. 2014; 26(3):279-288. DOI: 10.3109/09540261.2014.890922

25. Mitchell DL, Bennett MJ, Manfrin-Ledet L. Spiritual development of nursing students: Developing competence to provide spiritual care to patients at the end of life. J Nurs Educ. 2006; 45(9):365-370

26. Timmins F, Neill F. Teaching nursing students about spiritual care: A review of the literature. Nurse Educ Pract. 2013; 13(6):499-505. DOI: 10.1016/j.nepr.2013.01.011

27. Corry DS, Lewis CA, Mallett J. Harnessing the mental health benefits of the creativity-spirituality construct: Introducing the Theory of Transformative Coping. Journal of Spirituality in Mental Health. 2014; 16(2):89-110. DOI: 10.1080/19349637.2014.896854

28. Corry DA, Mallett J, Lewis CA, Abdel-Khalek AM. The creativityspirituality construct and its role in transformative coping. Mental Health, Religion \& Culture.2013; 16(10):979-990. DOI: $10.1080 / 13674676.2013 .834492$ 
29. Faul F, Erdfelder E, Lang A, Buchner A. G*Power (Version 3.1.9.2) [Computer software]. 2007.

30. Wagnild G. The Resilience Scale user's guide for the U.S. English version of the Resilience Scale and the 14-Item Resilience Scale (RS-14) [User's guide]. Worden, MT: Resilience Center. 2016

31. Burnett HJ Jr, Helm HW Jr. Relationship between posttraumatic stress disorder, resilience, and religious orientation and practices among university student earthquake survivors in Haiti. Int J Emerg Ment Health. 2013; 15(2):97-104.

32. Oladipo SE, Idemudia ES. Reliability and validity testing of Wagnild and Young's Resilience Scale in a sample of Nigerian youth. Journal of Psychology.2015; 6(1): 57-65.DOI: 10.1080/09764224.2015.11885524

33. King DB. Rethinking claims of spiritual intelligence: A definition, model, \& measure (Unpublished doctoral dissertation). Trent University, Peterborough, Ontario, Canada. 2009.

34. Emmons RA. Spirituality and intelligence: Problems and prospects. The International Journal for the Psychology of Religion. 2000; 10(1):57-64. DOI: 10.1207/S15327582IJPR1001_6

35. Wan Zulkifi WN, Ishak NA, Mat Saad ZB. The Spiritual Intelligence Self Report Inventory (Sisri 24) instrument reliability among delinquent teenagers. IOSR Journal of Humanities and Social Science. 2017; 22(7):44-447.

36. King DB, DeCicco TL. A viable model and self-report measure of spiritual intelligence. International Journal of Transpersonal Studies. 2009; 28(1):68-85.

37. Ahoei K, Faramarzi M, Hassanzedeh R. The relationship between spiritual intelligence and psychological well-being in women with breast cancer. Shiraz E-Medical Journal. 2017; 18(10): e15103. DOI: $10.5812 /$ semj.15103
38. Anbugeetha D. An analysis of the Spiritual Intelligence Self Report Inventory (SISRI). International Journal of Management. 2015; 6(7):25-36. DOI: 10120150607004

39. Botma Y. Nursing student's perceptions on how immersive simulation promotes theory-practice integration. International Journal of Africa Nursing Sciences. 2014; 1(1):1-5. DOI: 10.1016/j. ijans.2014.04.001

40.Scammell J. Resilience as part of nursing education: Supporting nurses in times of austerity. Br J Nurs. 2017; 26(13):772. DOI: 10.12968/bjon.2017.26.13.772

41. Robert Wood Johnson Foundation. Nearly one in five new nurses leave first job within a year, according to survey of newly-licensed registered nurses. 2014.

42. American Association of Colleges of Nursing. CARES: Competencies and recommendations for educating undergraduate nursing students preparing nurses to care for the seriously ill and their families. 2016

43. Barbato Gaydos HL. The living end: Life journeys of hospice nurses. Journal of Hospice \&Palliative Nursing. 2018; 6(1):17-26.

44. Nelson R. Replicating real life: Simulation in nursing education and practice. American Journal of Nursing. 2016; 116(5):20-21.

45. Ormsby A, Harrington A, Borbasi S. 'You never come back the same': The challenge of spiritual care in a deployed military nursing context. J Clin Nurs. 2017; 26(9-10):1351-1362. DOI: 10.1111/ jocn.13685 